\title{
5.11
}

\section{Nova abordagem de fiscalização em denúncias sanitárias consideradas de baixo risco}

New fiscalization's method in low risk sanitary complaints

\section{Cristina Silva Marins.}

Nutricionista, Especialização em Gestão da Vigilância Sanitária. Prefeitura do Município de São Bernardo do Campo. Brasil.

\section{Claudio Ferreira.}

Enfermeiro, Especialização em Gestão de Serviços Públicos de Saúde. Prefeitura do Município de São Bernardo do Campo. Brasil.

Elaine Atanes de Jesus.

Enfermeira, Especialização em Gestão de Serviços Públicos de Saúde. Prefeitura do Município de São Bernardo do Campo. Brasil.

Resumo: A vigilância sanitária deve ser concebida como um espaço de exercício de cidadania e controle social, sendo transformadora da qualidade dos produtos, processos e das relações sociais; exige uma ação abrangente e requer plena consciência para um adequado gerenciamento de risco sanitário. Essa relação deve estar fundamentada na noção de cidadão, sujeito de direitos, e não somente de consumidor. As pessoas devem ser consideradas como iguais em seus direitos, mesmo tendo diferentes posições ou valores socioculturais. As ações de vigilância sanitária visam à promoção e proteção da saúde como qualidade de vida, orientada pela noção de 'risco sanitário', referindo-se à possibilidade de dano, agravo ou efeito adverso à saúde, relacionado a procedimentos, produtos e serviços. Deve sempre visar uma maioria de pessoas. No processo de trabalho da vigilância sanitária, devese observar o princípio do contraditório e da ampla defesa, legitimizado pela possibilidade de resposta e utilização de todos os meios de defesa admitidos em Direito. Pensando nisso, foi implantada uma nova metodologia de atendimento às denúncias consideradas de baixo risco sanitário que evita o deslocamento da equipe de fiscalização para verificar questões extremamente pontuais, substituído pela convocação dos responsáveis pelos estabelecimentos à Central de Atendimento ao Cidadão e notificá-los sobre a denúncia. Essa metodologia vem trazendo resultados positivos, tanto para o órgão fiscalizador como para a população.

Palavras chave: Vigilância sanitária; denúncias; saúde e direito.

Key-words: sanitary surveillance; complaint; health and law. 


\section{Introdução}

A saúde é um direito social apresentado na Constituição Federal de 1988, onde neste também foi instituído do Sistema Único de Saúde - SUS, a fim de concretizar esse direito. A Lei Orgânica da Saúde - Lei ํํ 8.080/90 que dispõe sobre as condições para promoção, proteção e recuperação da saúde, a organização e o funcionamento dos serviços correspondentes, afirma no artigo 6ำ que a vigilância sanitária (VISA) está incluída no campo de atuação do SUS. Entende-se por vigilância sanitária um conjunto de ações capaz de eliminar, diminuir ou prevenir riscos à saúde e de intervir nos problemas sanitários decorrentes do meio ambiente, da produção e circulação de bens e da prestação de serviços de interesse da saúde, abrangendo:

I - o controle de bens de consumo que, direta ou indiretamente, se relacionem com a saúde, compreendidas todas as etapas e processos, da produção ao consumo; e

II - o controle da prestação de serviços que se relacionam direta ou indiretamente com a saúde.

A vigilância sanitária por apresentar um caráter de natureza preventiva deve possuir instrumentos e formas de atuação visando o controle do risco sanitário dos produtos e serviços ofertados. Entende-se o risco sanitário como possibilidade de dano ou agravo, de efeito adverso à saúde, relacionado a procedimentos, produtos e serviços. A priorização da ação de vigilância sanitária deve sempre visar um maior número de pessoas, ou seja, a ética requer a maximização dos benefícios, e enseja que a conduta humana, seja eticamente correta, devendo sempre objetivar "o maior bem para o maior número de pessoas" (Brandão, 2005).

A vigilância sanitária deve ser concebida como um espaço de exercício de cidadania e controle social, por sua capacidade transformadora da qualidade dos produtos, processos e das relações sociais e a sua natureza exige uma ação abrangente no campo interdisciplinar e interinstitucional (Lucchese, 2006).

A interação com a sociedade requer uma plena consciência para um adequado gerenciamento de risco sanitário e esta relação deve estar fundamentada na noção de cidadão, sujeito de direitos, e não somente de consumidor. A ideia é de que as pessoas sejam consideradas como iguais em seus direitos, mesmo quando tenham diferentes posições ou valores socioculturais (Fortes, 2006). 
O Código de Defesa do Consumidor brasileiro que prevê sobre a proteção do consumidor vem corroborar com as legislações sanitárias reafirmando a responsabilidade do produtor pela qualidade do produto ou serviço ofertado no mercado, tornando, também, o consumidor um sujeito de direito, na ação de denunciante (Costa, 2003).

Com o número elevado e crescente de denúncias recebidas pela vigilância sanitária, e em especial, reclamações voltadas para área de alimentos que gira em torno de 30 reclamações por mês, sendo essas de variados graus de risco sanitário passando dos mais baixos até os mais elevados, e sabendo-se da prioridade para o atendimento in loco das que representam risco elevado à saúde publica, é notório que as denúncias de menor gravidade permaneçam sem atendimento por um maior período de tempo.

Além disso, as atividades de vigilância sanitária para atender denúncias e outras demandas imediatas dificultam o planejamento e programação de ações estratégicas e sistematizadas, bem como ações educativas e orientadoras (I Conferência Nacional de Vigilância Sanitária, 2001).

\section{Objeto}

Objetivo do trabalho é apresentar a nova metodologia no atendimento de denúncias de menor risco sanitário realizadas por munícipes.

\section{$3 \quad$ Metodologia}

Pensando em uma forma de agilizar esse atendimento, foi estabelecido uma nova metodologia e forma de abordagem para 0 atendimento a denúncias consideradas de baixo risco sanitário. A Seção de Vigilância e Fiscalização de Alimentos da Prefeitura do Município de São Bernardo do Campo decidiu que, ao invés de mobilizar a equipe técnica de fiscalização até o estabelecimento para verificar questões de menor risco e extremamente pontuais - situações essas que nem sempre podem ser constatadas no momento da inspeção, tais como: lixo acondicionado na calçada de forma inadequada e presença de animais domésticos no estabelecimento - optou por convocar o responsável pelo estabelecimento denunciado a comparecer à Rede Fácil-Central de Atendimento ao Cidadão (CAC) para notificá-lo sobre a denúncia. 
A Rede Fácil-Central de Atendimento ao Cidadão oferece vários tipos de serviços da Prefeitura de São Bernardo do Campo, inclusive plantão técnico de diversas áreas, compreendendo também, o atendimento técnico de vigilância sanitária. Esse plantão da vigilância sanitária tem como objetivo sanar dúvidas dos proprietários ou responsáveis pelos estabelecimentos sujeitos à vigilância sanitária e atendimentos diversos como fornecimento de numeração para receituário controlado pela Portaria 344/98, entrega de documentações, abertura e encerramento de livros, vistas de processos e outros serviços relacionados. Para otimizar a utilização do tempo e espaço do plantão técnico, incluiu-se o atendimento da denúncia de baixo risco no local.

Adotou-se a seguinte forma para o atendimento desta demanda: as denúncias de supostas irregularidades de caráter sanitário percebidas pelo cidadão são recebidas pela Ouvidoria da Secretaria Municipal de Saúde e encaminhadas para a Seção de Vigilância e Fiscalização de Alimentos para uma classificação de risco. A partir daí, as reclamações que forem classificadas como menor risco sanitário são separadas e encaminhadas para a equipe técnica.

Para realizar o atendimento das denúncias de menor risco, o técnico primeiramente verifica se o estabelecimento já possui licença sanitária ou protocolo de solicitação da mesma, onde é possível esta constatação de acordo com as informações passadas pelo denunciante, tais como endereço e nome fantasia do reclamado. No caso em que o estabelecimento encontra-se regularizado, a localização do proprietário é mais fácil, pois os dados são mantidos no sistema de cadastro e informação da vigilância sanitária. Caso contrário, a Seção de Vigilância e Fiscalização de Alimentos depende de outros meios para realizar contato com o estabelecimento, utilizando na maioria das vezes os sites de busca, para localização de telefone e, entrar em contato com o responsável. Quando não é possível encontrar o telefone, o motoboy da prefeitura é encaminhado ao endereço com uma convocação para que o responsável do estabelecimento compareça ao plantão técnico na CAC, em dia e horário determinados para o atendimento. Em ambos os casos o responsável é informado que a convocação é para esclarecimentos sobre a denúncia recebida contra o estabelecimento e que seu comparecimento é obrigatório. 
Dependendo da quantidade de estabelecimentos a serem convocados são necessários dois técnicos para atender toda a demanda, inclusive a da rotina do plantão. No geral, o tempo de atendimento é em torno de 15 a 30 minutos.

No dia do agendamento são enviados para a CAC os processos existentes e o técnico leva ao plantão os espelhos de demanda (denúncias) e os termos de compromisso, documentos estes utilizados para comunicar ao denunciado o teor da denúncia e o prazo definido para regularizar as prováveis irregularidades. Caso o estabelecimento não possua licença, é solicitado neste documento a regularização da situação cartorial.

Durante o atendimento o responsável toma ciência do teor da denúncia através do termo de compromisso lavrado pelo técnico com prazo, que normalmente é de 15 dias, para comprovação de que solucionou o problema ou que a denúncia não procede. Assim é dada ao dono do estabelecimento, a oportunidade de demonstrar para a Seção de Vigilância e Fiscalização de Alimentos que a denúncia não é procedente ou, se for, que já foi feita a adequação do local ou ações que serão tomadas. Desta forma evitando-se o deslocamento da equipe técnica de fiscalização até o local. Esse procedimento dá ao responsável o direito de se defender.

Quanto às impressões da equipe, foi possível observar que, no primeiro momento do atendimento o responsável se apresenta inconformado e, muitas vezes até agressivo não aceitando a denúncia. Às vezes já chega ao agendamento referindo saber quem foi que o denunciou, falando do concorrente, dos vizinhos, dos invejosos e, quando tomam ciência do teor da denúncia, muitas vezes acham um absurdo. Falam que não procede que é tudo mentira e chegam a insinuar que a fiscalização deveria ir até o estabelecimento para verificar que é engano. Nesse momento, a tática é deixar que o responsável desabafe e depois conduzir a conversa explicando que o motivo da convocação para atendimento é justamente para proporcionar o direito e a oportunidade de defesa.

É explicado também que, quando o estabelecimento denunciado passa por uma inspeção in loco, esta é feita de maneira integral e, não somente focada no motivo da denúncia. Ou seja, muitas vezes pode-se encontrar outras irregularidades e estas podem levar às penalidades previstas em lei. Geralmente essa abordagem já é suficiente para que o responsável se acalme e assim é dado prosseguimento ao atendimento. $\mathrm{O}$ mesmo é informado sobre as legislações pertinentes ao 
estabelecimento, as quais ele deve consultar para melhorar a qualidade de seu estabelecimento. É sugerido que após a leitura das legislações o denunciado procure adequar seu estabelecimento para que, em futuras inspeções, o mesmo não venha a ter surpresas desagradáveis. Também é orientado sobre as vantagens de estar trabalhando dentro da legalidade e que, dessa forma, a qualidade do estabelecimento só tem a melhorar. Ressalta-se o fato de que manter o estabelecimento de acordo com as normas e em condições satisfatórias de funcionamento é um dever do proprietário e que, as adequações devem ser feitas para o melhor atendimento ao seu cliente e não somente por uma exigência dos fiscais da vigilância.

O proprietário é orientado sobre como responder o termo de compromisso assinado, devendo o estabelecimento juntar documentos comprobatórios das medidas tomadas a respeito da denúncia ou algo que comprove que aquela reclamação não procede. Os documentos comprobatórios devem ser juntados ao processo de licença sanitária do estabelecimento, e caso o mesmo ainda não tenha o processo aberto, é orientado para que proceda a abertura do processo para licença sanitária junto a VISA. Esses documentos podem ser fotos, notas fiscais, certificados ou declaração de próprio punho.

Após a juntada dos documentos comprobatórios, os mesmos são analisados pela equipe técnica. Na maioria das vezes os documentos juntados ao processo são fotos provando as medidas tomadas. Como exemplos citamos as provas juntadas: tela milimétrica que foram instaladas nas janelas, lixeiras com instalação de grade, fechamento de vão dos telhados e telas nas aberturas, instalação de alguma placa no estabelecimento e até mesmo criação de um estacionamento para cães com ganchos para coleira e bebedouros com água, ação tomada por um proprietário de um mercado de bairro que foi denunciado por permitir que seus clientes frequentassem o local com seus animais de estimação. Outros documentos, como certificado de controle de praga, planilhas de controle de temperatura de equipamentos, certificados de treinamento, entre outros também são juntados aos processos, conforme o tipo de denúncia realizada contra o estabelecimento.

\section{$4 \quad$ Resultados}

Durante esse curto período de atendimento, entre abril a junho de 2013, com essa nova abordagem foram realizados 23 atendimentos dos quais 16 apresentaram 
retorno e, desses, 7 abriram processo na VISA com solicitação de licença sanitária, saindo da clandestinidade.

Além desses resultados prévios, pretende-se realizar mais avaliações objetivas acompanhando o desenvolvimento desta nova metodologia, a fim de concluir sobre a eficácia do sistema proposto.

\section{Discussão}

Apesar da nova abordagem requerer inúmeras ações tais como: classificação das denúncias de acordo com risco sanitário, verificação de regularização cartorial do estabelecimento, levantamento de processos e legislações, realização de convocação, trabalho de convencimento, avaliação dos documentos anexados como resposta à notificação, podemos considerar que essa ação otimiza tempo, técnicos e recursos (viatura), promovendo o atendimento de um maior número de denúncias em menor tempo.

Esse tipo de abordagem pode parecer desgastante, mas quando verificou-se os retornos dos proprietários, o trabalho se tornou gratificante sendo que alguns chegam a elogiar a forma como foram tratados e agradecem pela oportunidade de poderem se defender ou de regularizar suas pendências.

Com isso, baseando-se no princípio da ampla defesa e do contraditório, o denunciado tomou a ciência da provável irregularidade, bem como teve a oportunidade para contestar a acusação ou produzir provas de seu direito, já que o responsável foi notificado da suposta irregularidade. Este princípio é assegurado pelo artigo 5º, inciso LV da Constituição Federal (1988), podendo também ser definido pela expressão audiatur et altera pars, que significa "ouça-se também a outra parte". É um corolário do princípio do devido processo legal, caracterizado pela possibilidade de resposta e a utilização de todos os meios de defesa em Direito admitidos (Wikipedia).

É possível verificar no cotidiano das instituições a predominância de uma cultura política conservadora, patrimonialista e autoritária, no qual o Estado desempenha o papel central (Pinheiro, 2004). Aliado a isso, existe a desinformação e o desinteresse do setor empresaria quanto às suas responsabilidades no atendimento à legislação sanitária (I Conferência Nacional de Vigilância Sanitária). Essa nova 
metodologia, como proposta inovadora no modelo de gestão, compartilha a responsabilidade sanitária entre comunidade e o poder público.

\section{Conclusões e lições aprendidas}

Percebemos que, na maioria das vezes, a convocação é atendida e o proprietário comparece na CAC para ter ciência do motivo da denúncia e essa estratégia vem apresentando um resultado bastante efetivo na correção de problemas bem pontuais, evitando o deslocamento da equipe técnica, considerando-se, ainda, que às vezes não seria possível constatar a irregularidade. Com isso otimizamos o trabalho, embora não deixemos de realizar uma ação de intervenção, pois, no momento em que o proprietário do estabelecimento tem o conhecimento de que seu estabelecimento foi denunciado, o mesmo tem a oportunidade de melhorar ou adequar algo que está incomodando o seu consumidor. Frente a uma equipe reduzida, essa estratégia tem contribuído bastante para ampliar o atendimento das denúncias da seção.

\section{Referências}

BRANDÃO, A.C.C. A Vigilância Sanitária como instrumento de cidadania. Rio de Janeiro. 31 mai. 2005. Acesso em 10 set. 2013. Disponível em: http://www.boaspraticasfarmaceuticas.com.br/vigilancia sanitaria e cidadania.asp

CONFERÊNCIA NACIONAL DE VIGILÂNCIA SANITÁRIA, 1, 2001, Brasília. Conferência Nacional de Vigilância Sanitária: relatório final. Brasília: Agência Nacional de Vigilância, 2001.

COSTA, E.A. Vigilância sanitária e proteção da saúde. In: ARANHA, M.I. Direito sanitário e saúde pública. Brasílila : Editora MS. 2003. p.179-206.

FORTES, P. A. C. Vigilância sanitária, ética e construção da cidadania. In: De SETA, M. H.; PEPE, V. L. E.; OLIVEIRA, G. O. de. Gestão e vigilância sanitária: modos atuais do pensar e fazer. Rio de Janeiro : Fiocruz, 2006. p. 61-69.

LUCCHESE, G. A vigilância sanitária no Sistema Único de Saúde. In: De SETA, M. H.; PEPE, V. L. E.; OLIVEIRA, G. O. de. Gestão e vigilância sanitária: modos atuais do pensar e fazer. Rio de Janeiro : Fiocruz, 2006. p. 33-47.

PINHEIRO, R. Democracia e Saúde: Sociedade Civil, Cidadania e Cultura Política. Physis: Revista Saúde Coletiva. Rio de Janeiro, 14(1):11-14, 2004.

PRINCÍPIO do contraditório e da ampla defesa. In: WIKIPÉDIA: a enciclopédia livre. Wikimedia, 2013. Acesso em: 10 set. 2013. Disponível em: <http://pt.wikipedia.org/wiki/Princ\%C3\%ADpio_do_contradit\%C3\%B3rio_e_da_ampla defesa>. 